\title{
NEODESENVOLVIMENTISMO E EDUCAÇÃO: UMA ANÁLISE DO PRONATEC AMBIENTAL'1
}

\author{
Thiago da Silva Oliveira² \\ Alexandre Maia do Bomfim ${ }^{3}$
}

\begin{abstract}
Resumo
Esse artigo aponta o avanço da conciliação entre interesses desenvolvimentistas e ambientalistas no Brasil, representado pelo projeto neodesenvolvimentista. Notamos uma educação ambiental mais preocupada com as vantagens econômicas que esse discurso pode oferecer, do que com os interesses socioambientais. Ao olharmos para o Curso Técnico em Meio Ambiente do Programa Nacional de Acesso ao Ensino Técnico e Emprego (Pronatec) vimos a materialização dessa perspectiva na Educação, desvelando uma concepção utilitarista do meio ambiente, correspondente a uma demanda específica do mercado brasileiro.
\end{abstract}

Palavras-chaves: Educação Ambiental Crítica; Neodesenvolvimentismo e Meio Ambiente; Pronatec.

\section{NUEVO DESARROLISMO Y EDUCACIÓN: UN ANÁLISIS DE PRONATEC}

\section{Resumen}

Este artículo señala el avance de la conciliación entre los intereses ambientalistas y de desarrollo económico en Brasil representados por el proyecto nuevo desarrollista. Observamos una educación ambiental más preocupada por las ventajas económicas que puede ofrecer este discurso que por los intereses directamente socioambientales. Al observar el Curso Técnico Ambiental del Programa Nacional de Acceso a la Educación Técnica y al Empleo (Pronatec), vimos la materialización de esta perspectiva, revelando una concepción utilitaria del medio ambiente que corresponde a una demanda específica del mercado brasileño.

Palabras-Claves: Educación Ambiental Crítica; Nuevo Desarrollismo y Medio Ambiente; Pronatec.

NEODEVELOPMENTALISM AND EDUCATION: AN ANALYSIS OF ENVIRONMENTAL PRONATEC

Abstract

This article show the advance of the the conciliation between the economic and environmentalist interests in Brasil represented by the neo-developmentalist project. We note an environmental education more concerned with the economic advantages that this discourse can offer than with the directly socioenvironmental interests. Looking at the Environmental Technical Course of the National Program for Access to Technical Education and Employment (Pronatec) we saw the materialization of this perspective, reveal a utilitarian conception of the environment that corresponds to a specific demand of the Brazilian market.

Keywords: Critical Environmental Education; New Developmentalism y Environment; Pronatec.

\footnotetext{
1 Artigo recebido em 07/10/2019. Primeira avaliação em 27/02/2020. Segunda avaliação em 11/03/2020. Aprovado em 18/04/2020. Publicado em 22/05/2020. DOI: https://doi.org/10.22409/tn.v18i36.38167

${ }^{2}$ Mestre em Ensino de Ciências pelo Programa Pós-graduação em Ensino de Ciências (Propec) do Instituto Federal de Educação, Ciência e Tecnologia do Rio de Janeiro (IFRJ) - Brasil. E-mail: thiagosilvaoliveira1989@gmail.com ORCID: 0000-0001-8855-470X

${ }^{3}$ Doutor em Ciências Humanas - Educação. Professor Associado II do Programa de Pós-graduação em Ensino de Ciências (Propec) do Instituto Federal de Educação, Ciência e Tecnologia do Rio de Janeiro (IFRJ) - Brasil. E-mail: alexandre.bomfim@ifri.edu.br ORCID: 0000-0002-5617-2229
} 


\section{Introdução}

Os modernos imaginavam que a vocação do ser humano é o desenvolvimento, em todas as áreas, e que isso se traduz por um projeto de progresso ilimitado. Ora, uma terra limitada não suporta um projeto ilimitado. (Leonardo Boff, 2012)

Esse trabalho é parte de uma pesquisa mais ampla que buscou compreender como fica a questão ambiental num projeto de desenvolvimento econômico estimulador do consumismo e qual é o limite de uma educação ambiental demarcada por esse ponto de vista. Aqui, nosso escopo é mais preciso, uma vez que nos concentraremos especificamente no Curso Técnico em Meio Ambiente do Programa Nacional de Acesso ao Ensino Técnico e Emprego (Pronatec), ofertado pelo Instituto Federal de Educação, Ciência e Tecnologia Fluminense (IFF).

O presente texto tem como objetivo refletir sobre uma educação ambiental que possa ser capaz de transformar efetivamente a realidade socioambiental. Partimos do pressuposto de que para realizar esse objetivo deve-se ter como requisito a compreensão mais aprofundada possível da realidade e, logo, das causas da degradação socioambiental. Neste trabalho chamaremos essa perspectiva de Educação Ambiental Crítica (EA-Crítica).

Para a Educação Ambiental se fazer crítica, conforme nossa compreensão, é necessário discernir os diferentes discursos ideológicos presentes no ato educacional, ou seja, não se pode ignorar os antagonismos de classe. Dessa forma, destacamos pontos importantes que devem ser considerados por uma proposta crítica, como: a permanente necessidade de resgate do humanismo; observação dos limites do desenvolvimento sustentável; a revisão permanente para evitar a conformação principalmente no ato educativo; a orientação de ataque permanente ao viés conservacionista; a crítica às ações higienizadoras e à culpabilização dos indivíduos; o apontamento dos principais responsáveis pela depredação ambiental; e o questionamento ao consumismo (cf. BOMFIM, 2014).

Desse ponto de partida, assumimos especialmente a crítica ao consumismo como direção para os nossos estudos, não apenas para seu caráter patológico evidente, reconhecível por todos, mas para o tipo que se instala na estrutura do 
sistema. Esse tipo "consumismo" que esteve presente inclusive no discurso do presidente Luís Inácio da Silva (Lula), na crise de 2008:

[O trabalhador] pensa assim: eu não vou fazer a compra porque eu tenho medo de perder o emprego. O que eu quero dizer é que ele corre o risco de perder o emprego se ele não comprar, porque ele não comprando o comércio não encomenda para indústria, que não produz, e sem produzir, não tem emprego [na indústria]. [Presidente Luís Inácio Lula da Silva em 2008, sobre a crise que abateu a economia mundial no final da primeira década do sec. XXI] (apud BOMFIM, 2010, p.11).

A constatação desse "consumismo estrutural" provoca na EA-Crítica a necessidade de compreender o panorama econômico no qual estamos inseridos, a sua relação com o meio ambiente e a consequência para a educação ambiental. No caso, considerando o momento histórico, sob a influência do projeto neodesenvolvimentista, em relação ao meio ambiente e à educação.

Vale dizer que entendemos o "neodesenvolvimentismo" como sendo as políticas de governo (especialmente as do período petista) voltadas para o crescimento econômico do país, considerando esses pontos extras: políticas de crédito popular e de economia social; transferências de renda direta; valorização do salário mínimo; atenção às políticas macroeconômicas (valorização da taxa de câmbio, meta de superávit primário, juros alto, entre outros); incremento de investimentos no mercado de commodities. Dizemos pontos extras porque foram somados ou confrontados aos três clássicos do desenvolvimentismo das décadas de 60 e 70: intervenção estatal, nacionalismo e industrialismo (este com uma guinada convergente ao agronegócio).

E outro item importante aos projetos neodesenvolvimentistas foi trazer cada vez mais pautas com objetivos voltados para o Desenvolvimento Sustentável (DS). Mas, qual a relação entre o desenvolvimento econômico e o meio ambiente nesta vertente e que educação ambiental seria essa, que não se oporia aos interesses neodesenvolvimentistas?

Para isso, vale uma ressalva para o conceito de Desenvolvimento Sustentável. Acreditamos que o conceito de Desenvolvimento Sustentável tem limites muito acentuados (vale conferir LAYRARGUES, 1997), a tal ponto que não é absolutamente divergente do projeto desenvolvimentista ou neodesenvolvimentista. Para a EA-crítica o Desenvolvimento Sustentável (visível até mesmo no termo) é pouco ambiental e muito econômico. A compreensão de que Desenvolvimento Sustentável é a maneira pela qual devemos explorar as condições que a natureza nos dá hoje sem que venhamos a comprometer o futuro das próximas gerações, o que aparentemente pode 
ser muito, se torna na verdade um discurso vazio, incapaz de revelar que práticas no fundo devemos obter hoje que não possam ter melhor resultado socioambiental. Ou seja, se insere facilmente num projeto desenvolvimentista ou neodesenvolvimentista (cf. LAYRARGUES, 1997; BOMFIM, 2010; BOFF, 2012).

Com esses pressupostos teórico-políticos que vamos enfrentar as questões que se impuseram para nós nas propostas neodesenvolvimentistas, especialmente as vividas com o Partido dos Trabalhadores no poder, a partir de seu programa educacional profissional mais significativo: o Programa Nacional de Acesso ao Ensino Técnico e Emprego (Pronatec). Utilizaremos como referenciais teóricos autores que trabalham com a perspectiva crítica da educação ambiental, como: Bomfim (2010), Guimarães (2012), Lima e Layrargues (2011) etc., além de nos alinharmos com autores que conciliam a questão ambiental ao materialismo dialético em outras frentes (CHESNAY e SERFATI, 2003; DELUIZ e NOVICKI, 2004; LOWY, 2008).

\title{
Pronatec e Meio ambiente: a educação ambiental neodesenvolvimentista
}

\begin{abstract}
A educação para além do capital visa a uma ordem social qualitativamente diferente. Agora não é só factível lançar-se pelo caminho que nos conduz a essa ordem como também necessário e urgente. Pois, as incorrigíveis determinações destrutivas da ordem existente tornam imperativo contrapor aos irreconciliáveis antagonismos estruturais do sistema do capital uma alternativa concreta e sustentável para a regulação da reprodução metabólica social, se quisermos garantir as condições elementares da sobrevivência humana. (MÉSZÁROS, 2008)
\end{abstract}

A elaboração do Pronatec, através da Lei ํํ 12.513 (BRASIL, 2011), se deu em um governo neodesenvolvimentista, que ficou caracterizado, entre outras particularidades, pela tentativa de conciliação de interesses antagônicos da sociedade brasileira (BRESSER-PEREIRA, 2013). O contexto de criação do Pronatec, em outubro de 2011, marcou um período de queda no crescimento econômico. Se no ano anterior (2010) o Brasil havia apresentado um crescimento de 7,5\%, no primeiro ano 
do governo Dilma Rousseff (2011) a economia cresceu mais modestamente a 2,7\% . Um dos argumentos usados pelos empresários e pela equipe técnica do governo para explicar essa queda do Produto Interno Bruto (PIB) brasileiro foi o limite imposto pela falta de mão-de-obra qualificada no Brasil. Todo investimento dispensado nos últimos anos pelo governo brasileiro teria desenvolvido novas demandas dos setores produtivos relacionadas à formação profissional. E como essas demandas não estavam sendo satisfeitas, a economia desacelerou. Por conta disso, autores e instituições de pesquisas diagnosticaram um "apagão da mão-de-obra" naquele momento do país (CASTIONI, 2013).

Por meio do Pronatec tentou-se oferecer ao mercado o "capital humano" necessário para sair da situação de baixo crescimento econômico. Coube ainda a esse programa de formação profissional, a iniciativa de seduzir os trabalhadores e estudantes com a promessa de ampla variedade de formação e emprego; assim como para os empresários, prometendo-Ihes trabalhadores em diversas prateleiras do mercado. Ventura, Lessa e Souza (2018) apontam que o Pronatec faz parte das políticas educacionais caracterizadas pela dualidade estrutural da educação, através da qual se oferta uma formação acadêmica intelectual às elites e uma formação profissional para os trabalhadores, porque, no fim das contas, há uma formação aligeirada para ocupação imediata dos postos de trabalho.

No projeto neodesenvolvimentista tentou-se ainda aliar a defesa de questões ambientais ao desenvolvimento econômico. Dizia-se que o crescimento sustentado de longo prazo só seria consolidado se fosse fundado em bases sustentáveis ambientalmente, rumo a transição para a economia verde (POCHMANN, 2013; MERCADANTE, 2010). O traço pragmático compreendido nesse pensamento se revela preocupado com o ponto de vista econômico e com a possibilidade de sair na frente no processo de elaboração de produtos "verdes", como se vê na afirmativa de Mercadante:

\footnotetext{
${ }^{4}$ Esses números foram retirados da série histórica do Produto Interno Bruto brasileiro produzida pelo Instituto Brasileiro de Geografia e Estatística (IBGE). Conferir no site: https://ww2.ibge.gov.br.

${ }^{5} \mathrm{O}$ conceito de capital humano, ou recursos humanos, segundo Frigotto (2010, p.51), "busca traduzir o montante de investimento que uma nação faz ou os indivíduos fazem, na expectativa de retornos adicionais futuros. Do ponto de vista macroeconômico, o investimento no "fator humano" passa a significar um dos determinantes básicos para o aumento da produtividade e elemento de superação do atraso econômico. Do ponto de vista microeconômico, constitui-se no fator explicativo das diferenças individuais de produtividade e de renda e, consequentemente, de mobilidade social."
} 
O país reúne condições extremamente favoráveis para se colocar na vanguarda da conciliação entre o equilíbrio ambiental e o direito ao desenvolvimento. Temos matriz energética relativamente limpa e uma das maiores biodiversidades do planeta. Estamos à frente no uso de algumas energias renováveis e temos condições de estimular o uso mundial de biocombustíveis, sem prejudicar a produção de alimentos e a preservação dos biomas. (MERCADANTE, 2010, p. 393 grifos nossos).

A tentativa de conciliação entre os interesses econômicos e ambientais transfere ao meio ambiente o papel de propulsor do desenvolvimento, como uma oportunidade econômica que o Brasil não poderia deixar de aproveitar, já que reuniria vantagens territoriais quando comparado a outros países.

Em suma, no projeto neodesenvolvimentista, a sustentabilidade aparece como um possível apêndice da questão econômica, podendo ser viabilizada quando for rentável e negligenciada quando não o for. Isso fica evidente nos trabalhos de Mercadante (2010), Pochmann (2013) Bresser-Pereira (2013), entre outros.

Um bom exemplo prático dessa subordinação de interesses foi documentado em uma entrevista que o Ministro Chefe da Secretaria-Geral da presidenta Dilma Rousseff, Gilberto Carvalho, concedeu para a BBC Brasil em 2014. Nessa ocasião, o ministro apontou que o governo não avançou no reconhecimento de terras indígenas por "falta de competência e clareza"; contudo, quando perguntado sobre a repressão dos protestos contra a usina de Belo Monte afirmou que:

quando você mantém um diálogo permanente - e instalamos lá uma casa de governo para dialogar - e se apela para ocupação de uma obra que tem interesse nacional, é dever do Estado enviar todos os esforços para que a obra retome o ritmo. ${ }^{6}$ (grifos nossos).

A fala de Gilberto Carvalho evidencia o caráter autoritário desse "interesse nacional" presente no discurso neodesenvolvimentista. Ao se desconsiderar, contraditoriamente, uma pauta que o próprio ministro diz defender, fica explícita a lógica de subordinação de interesses contrários aos seus, assim como fica clara a hegemonia do desenvolvimento econômico sobre a sustentabilidade ambiental.

A vertente ambiental do Pronatec, uma cooperação entre o Ministério da Educação (MEC) e o Ministério do Meio Ambiente (MMA), traz consigo essa lógica neodesenvolvimentista em seus documentos. Um exemplo está justamente no

\footnotetext{
${ }^{6}$ Disponível em: http://www.bbc.com/portuguese/noticias/2014/11/141108_entrevista_gilberto_jf_fd. Acesso em: 19 mar. 2020.
} 
"Catálogo de Cursos do Pronatec de Interesse da Área Ambiental"7. Esse catálogo apresenta todos os cursos demandados pelo MMA; ao todo, o documento separa 12 eixos tecnológicos, sendo quase metade dos cursos ofertados $(35 \mathrm{em} 86$ ) relacionados ao eixo "Recursos Naturais". Tratar o meio ambiente como um recurso natural significa concebê-lo de forma economicista, ou seja, olhar para a natureza como fonte de matéria prima disponível para o usufruto humano, deixando de considerar os problemas ocasionados pela retirada desses recursos.

A demanda do Pronatec pelo MMA teve como pano de fundo a sanção da lei no 12.852, de 5 de agosto de $2013^{8}$, que Instituiu o Estatuto da Juventude e firmou o Sistema Nacional de Juventude (SINAJUVE). Por conseguinte, foi organizada a Coordenação de Juventude com vista a criar um Plano Nacional de Juventude e Meio Ambiente $\left(\mathrm{PNJMA}^{9}\right)$, que integra o SINAJUVE, instituído pela lei supracitada. A parceria com o MEC aparece como uma oportunidade para o MMA colocar em prática - Estatuto da Juventude, que traz em seu texto a necessidade da criação de programas de educação ambiental destinados aos jovens (art. 36).

De modo geral, as preocupações apresentadas por esses documentos podem se resumir nos seguintes eixos: superpopulação, desemprego da juventude, aumento da temperatura planetária e, por consequência deste último, a escassez de bens naturais essenciais para o desenvolvimento das nações. $O$ tom neomalthusiano se evidencia em inúmeras reflexões, inclusive no posicionamento defendido pelo MMA, através desses documentos, a saber: deseja-se um "desenvolvimento ambientalmente adequado, socialmente justo e economicamente viável, incorporando questões relativas à ética, política e cultura" (BRASIL, 2013, p.35 grifos nossos).

Não se propõe uma outra lógica de desenvolvimento ${ }^{10}$, apenas se almeja amenizar os problemas relacionados ao modelo atual. É necessário cautela quando

\footnotetext{
${ }^{7}$ Disponível

em: http://www.mma.gov.br/images/arquivos/responsabilidade_socioambiental/juventude/Catalogo_Mei oAmbiente.pdf. Acessado em 27/04/2019.

${ }^{8}$ Disponível em: http://www.planalto.gov.br/ccivil_03/_ato2011-2014/2013/lei//12852.htm. Acessado em 27/04/2019.

${ }^{9}$ Disponível

http://www.mma.gov.br/images/arquivos/responsabilidade_socioambiental/juventude/publicacao_versa o3.pdf. Acessado em 27/04/2019.

${ }^{10}$ Cautelosamente não abandonamos o termo "desenvolvimento", talvez devêssemos, mas por ora, entendemos que a nossa crítica está sobre os termos "neodesenvolvimentismo" e "desenvolvimentismo" por conta do seu sufixo "ismo", o que revelaria mais seus projetos extremos de submissão do ambiente.
} 
se trata dessa vertente, devemos, por exemplo, nos perguntar para quem seria adequado esse desenvolvimento sustentável, pois numa sociedade regida por interesses antagônicos o que é adequado para um grupo pode não ser adequado para outro. Além disso, a palavra "adequado" pode significar apenas uma adaptação, ao invés da transformação desse desenvolvimento classificado pelo próprio relatório como "predatório, injusto e excludente" (Ibid. p. 34). Da mesma forma, o termo "socialmente justo" não informa muito sobre seus objetivos, uma vez que a justiça guiada pelos moldes da sociedade capitalista, baseada na exploração do trabalho e da natureza, faz prevalecer o interesse do lucro crescente, consequentemente da própria exploração. Por fim, o termo "economicamente viável”, pode servir como uma delimitação do que pode ou não ser feito, pois, se levarmos em consideração o modelo que temos visto é economicamente viável todo investimento que não prejudica o lucro dos capitalistas.

Podemos concluir com isso, que a posição do MMA, expressa nos documentos que originaram o Pronatec Ambiental, reforça o pensamento neodesenvolvimentista em relação ao meio ambiente e transfere essa visão para os cursos de vertente ambiental do programa.

\section{Curso Técnico em Meio Ambiente}

Neste momento nos debruçaremos no Curso Técnico em Meio Ambiente do Pronatec ofertado pelo Instituto Federal de Educação, Ciência e Tecnologia Fluminense (IFF) ${ }^{11}$, da modalidade subsequente. Nosso objetivo é notar até que ponto os pressupostos neodesenvolvimentistas relacionados à formação profissional do trabalhador e à questão ambiental se fazem presentes. Para isso utilizaremos o Projeto Pedagógico do Curso (PPC) Técnico em Meio Ambiente.

O texto do PPC inicia com a apresentação da instituição que o oferece, exibindo sua gênese, identidade e missão institucional. O documento identifica o Pronatec como a mais ambiciosa reforma já realizada na Educação Profissional e Tecnológica (EPT) brasileira e converge os seus objetivos institucionais aos do programa. Sendo assim,

\footnotetext{
${ }^{11}$ Apesentamos aqui o estudo que fizemos com esse curso no IFF, mas também fizemos com outras Instituições, inclusive com a nossa, IFRJ. Trouxemos esse aqui por conta do distanciamento que conseguimos obter e desejávamos compartilhar.
} 
pode-se afirmar desde o início que há uma compatibilidade do curso aos pressupostos formativos do Pronatec ambiental.

Para o PPC, esse profissional pode trabalhar em quaisquer áreas que escolher, uma vez que ele deverá desenvolver valores capazes de o levar a compreender o meio social, político e econômico em que vive. Além de "ter consciência das necessidades e valores de responsabilidade social associada aos conceitos de justiça e ética" (IFF, 2015, p. 21). Neste ponto parece que o documento defende uma formação ampliada de educação, com características emancipadoras, o que parece entrar em contradição com os pressupostos da educação que encontramos nos documentos do Pronatec e em seus críticos.

A proposta pedagógica do curso é organizada em três núcleos básicos de formação, a saber: (1) núcleo básico de formação do técnico, onde são desenvolvidos os componentes curriculares de nível básico necessários a qualquer formação profissional; (2) núcleo básico do eixo tecnológico, por meio do qual são apresentados os componentes curriculares do eixo tecnológico "Ambiente e Saúde"; e o (3) núcleo específico do curso, que compreende a formação do técnico em Meio Ambiente. Do total de 15 disciplinas 10 fazem parte do núcleo específico do curso, ou seja, são disciplinas técnicas; duas são do núcleo básico de formação; e, três do eixo tecnológico. A seguir apresentamos um resumo da matriz do curso e sua carga horária total prevista ${ }^{12}$.

Tabela 1 - Matriz do Curso Técnico em Meio Ambiente

\begin{tabular}{|c|c|c|}
\hline \multirow{2}{*}{ Núcleos Integradores } & Componentes curriculares & $\begin{array}{c}\text { Carga horária das } \\
\text { disciplinas (em } \\
\text { horas) }\end{array}$ \\
\hline Núcleo básico de formação & Português instrumental & 60 \\
\cline { 2 - 3 } & Empreendedorismo & 60 \\
\hline \multirow{2}{*}{$\begin{array}{c}\text { Núcleo básico do eixo } \\
\text { tecnológico }\end{array}$} & Ecologia & 60 \\
\cline { 2 - 3 } & Química Ambiental & 60 \\
\hline \multirow{2}{*}{\begin{tabular}{c} 
Núcleo específico do curso \\
\cline { 2 - 3 }
\end{tabular}} & Educação Ambiental & 60 \\
\cline { 2 - 3 } & Hidrologia & 60 \\
\cline { 2 - 3 } & Poluição e Controle Ambiental & 60 \\
\hline
\end{tabular}

${ }^{12}$ É importante deixar claro que esse trabalho se dedicou exclusivamente ao currículo oficial do curso positivado no PPC; ou seja, as análises que ora se apresentam não foram confrontadas à prática cotidiana da instituição em questão. Isso significa que nem o currículo real e nem o currículo oculto serão abordados em nossas problematizações. 


\begin{tabular}{|c|c|c|}
\hline \multirow{4}{*}{} & Legislação Ambiental & 60 \\
\cline { 2 - 3 } & Microbiologia Ambiental & 60 \\
\cline { 2 - 3 } & Manejo e Conservação de Recursos Naturais & 60 \\
\cline { 2 - 3 } & Gestão Ambiental & 60 \\
\cline { 2 - 3 } & Recuperação de Áreas Degradadas & 60 \\
\cline { 2 - 3 } & Avaliação de Impactos Ambientais & 60 \\
\cline { 2 - 3 } & Saneamento Ambiental & 60 \\
\hline Projeto final & 60 \\
\hline CARGA HORÁRIA TOTAL DO CURSO & 960 \\
\hline
\end{tabular}

Fonte: Elaborada pelos autores com base no PPC do Curso Técnico em Meio Ambiente (IFF, 2015)

Nota-se o quanto o curso é direcionado mais para uma formação técnica do profissional, do que para os aspectos humanísticos/sociais intrínsecos aos problemas ambientais. Podemos inferir, com isso, que há maior interesse em formar um profissional que se encaixe no mercado de trabalho do que alguém que vá questionar as contradições da sociedade capitalista. Da mesma forma, o PPC defende que a formação de um técnico em meio ambiente deve atender às exigências de um mercado de trabalho em constante transformação, portanto, os profissionais formados devem ter competências para lidar com essas "complexas" mudanças que se demanda deles.

O grande desafio, portanto, será o de traduzir, institucionalmente, o objetivo de formar profissionais que estejam aptos para o mercado de trabalho e que também sejam capazes de dar continuidade aos estudos, uma vez que a nova realidade do mundo do trabalho [...] passou a exigir da Educação Profissional o desenvolvimento de conhecimentos, saberes e competências profissionais cada vez mais complexos. (IFF, 2015, p.7)

Por conseguinte, o documento afirma que a nova formação do educando "deverá atender a quatro premissas básicas: formação científico-tecnológica sólida, flexibilidade para as mudanças, empreendedorismo e educação continuada." Ou seja, através da organização pedagógica por competência se espera que o egresso adquira as quatro premissas básicas, citadas anteriormente, para a inserção no mercado de trabalho, e que saiba ainda se adaptar às constantes transformação do mercado.

Essa manifestação de uma educação mais flexível faz parte de uma nova concepção do trabalho baseada na reestruturação produtiva do capitalismo. Acácia Kuenzer (2005) aponta que, se antes, no modelo Taylorista/Fordista, a finalidade da produção era a massificação das mercadorias, com tecnologia estável e com processos rigidamente ordenados, que não permitiam mudanças ou criatividade para 
a maioria dos trabalhadores; na reestruturação atual, chamada de regime de acumulação flexível, importa ao trabalhador mais a adaptabilidade das funções laborais, as competências cognitivas ou comportamentais, a capacidade de se submeter ao novo e a conformação à instabilidade.

A busca por eficiência no processo de produção exige novos trabalhadores e novas formas de trabalho, o que aumenta o desemprego estrutural, flexibiliza as leis trabalhistas e explora ainda mais os trabalhadores. Exige-se um trabalhador polivalente, capaz de solucionar problemas e produzir eficientemente em todas as situações. Consequentemente, é a adaptação aos novos ritmos e processos, que surgem dinamicamente na sociedade, como as novas tecnologias e linguagens, que devem pautar as relações entre o conhecimento e o trabalho. Duarte (2001), indica que a pedagogia das competências segue essa lógica, uma vez que não são os conteúdos que interessam, mas as competências e as habilidades dos estudantes.

A maioria das disciplinas expostas no PPC do curso apresenta o meio ambiente como fonte de recursos que deve ser gerido em favor do homem ou da sociedade de mercado, isto é, tem-se uma visão da natureza como depósito de recursos naturais. Esse ponto de vista vai ao encontro da perspectiva, vista anteriormente, do MMA e do projeto neodesenvolvimentista. Embora a maioria das disciplinas seja de caráter técnico, consideramos que algumas delas permitem análises de conflitos socioambientais relacionados à reprodução do capital, como a disciplina "Meio Ambiente Urbano e Seus Impactos Ambientais", mas, como a relação não é imediata, o professor deve conhecer e estar interessado em apresentar esse ponto de vista para os alunos. Segue os conteúdos exibidos na ementa dessa disciplina:

Teorias e conceitos referentes aos impactos ambientais em áreas urbanas; [...] a ocupação do solo e os riscos ambientais; os movimentos de massa e sua influência na dinâmica ambiental urbana; erosão de solos e impactos ambientais; [...] danos ambientais urbanos decorrentes da poluição sonora, dos empreendimentos imobiliários, da exploração mineral, das obras públicas, da deficiência no sistema de esgotamento sanitário, da ocupação irregular do solo urbano, das atividades industriais, do uso irregular de produtos tóxicos e da disposição final do lixo (IFF, 2015, p. 41).

Nota-se que os temas propostos são diversos e permitem uma condução crítica das aulas, podendo-se problematizar assuntos como a especulação imobiliária, a crescente demanda por energia, a desigualdade no acesso à água etc. Além de permitir a reflexão sobre os agentes poluidores segundo sua capacidade de poluição 
e suas responsabilidades de reverter o quadro de destruição do meio ambiente. Já em 2012, Boff, em seu estudo sobre sustentabilidade, nos trazia informações importantes sobre essa desigualdade, como: as 500 milhões de pessoas mais ricas (7\% da população mundial) respondem por $50 \%$ das emissões de gases de efeito estufa; os 3,4 bilhões mais pobres (50 \% da população) respondem apenas por 7\% das emissões produtoras do aquecimento global; se quiséssemos hipoteticamente universalizar para toda a humanidade o nível de consumo que os países ricos como os Estados Unidos, a União Europeia e o Japão desfrutam, seriam necessários cinco planetas Terra; o cálculo feito em 2010 dava 7,9 hectares globais para um estado-unidense médio, 4,7 para um europeu, 2,1 para um brasileiro e 1,4 para um africano.

Outro ponto importante notado na análise do PPC foi a ausência da relação entre o tema "saúde" e "meio ambiente". A falta dessa associação espanta, uma vez que esse é o eixo tecnológico do curso, nem mesmo nas ementas das disciplinas essa relação se faz presente.

$\mathrm{Na}$ justificativa do curso, o documento ressalta o contexto econômico da região em que se encontra a instituição e, logo depois, aponta o quanto o Técnico em Meio Ambiente será bem-vindo pelo mercado:

\begin{abstract}
De acordo com o plano de Desenvolvimento Sustentável do Norte do Estado do Rio de Janeiro de março de 2010, a indústria tem sido o principal elemento no crescimento do PIB da região, gerando impacto através dos empregos gerados, direta e indiretamente, da massa de salários pagos à população e dos impostos [...] Desta forma, o papel do técnico em meio ambiente torna-se importante na atualidade, visto que é um profissional habilitado para lidar com as transformações ambientais e os impactos relacionados a estas mudanças[...] O acelerado crescimento urbano e industrial e as práticas agrícolas consolidadas a décadas em nossa região geram o desafio de conciliar o crescimento econômico com a conservação ambiental (IFF, 2015).
\end{abstract}

A justificativa do PPC aponta um estilo conciliador entre o crescimento econômico e a conservação ambiental. Já vimos anteriormente que essa estratégia de conciliação faz parte de um projeto de reorganização da estrutura produtiva que aceita as reivindicações ambientais apenas quando são "economicamente viáveis". Sendo assim, não suportam os questionamentos estruturais feitos pelo viés crítico da educação ambiental expostos neste trabalho. 
Os objetivos do curso também vão ao encontro de uma formação nos limites do desenvolvimento capitalista, inclusive, dando apoio para que ele ocorra. Abaixo estão descritos os objetivos gerais e específicos do curso:

O Curso Técnico em Meio Ambiente tem por objetivos propiciar maiores oportunidades de qualificação na área ambiental; ampliar a oferta de capacitação e treinamento na região; apoiar a capacitação das empresas em sua adequação às exigências e princípios do desenvolvimento sustentável; desenvolver a capacidade de observação, planejamento, problematização, contextualização e interpretação da realidade, buscando soluções para os problemas concernentes à prática profissional; promover a interação entre ciência/tecnologia/produção; buscar soluções aos desafios e problemas da prática profissional com cidadania e respeito ao meio ambiente e aos princípios éticos, estéticos e políticos; ter capacidade de atender às demandas do mercado de trabalho da Área de Meio Ambiente. (IFF, 2015, p. 6).

Objetivos específicos:

- Proporcionar formação pessoal e profissional, através de atividades que visem ao desenvolvimento tecnológico.

- Oferecer formação específica para os profissionais já atuantes no mercado, possibilitando crescimento e aprimoramento profissional.

- Desenvolver aptidões para a vida produtiva.

- Formação de profissionais para promover a operacionalização e aplicação de modernas metodologias e tecnologias de desenvolvimento sustentável nos centros urbanos e adequação dos empreendimentos industriais respeitando a legislação ambiental em vigor.

- Promover a qualificação de recursos humanos para o diagnóstico das condições ambientais nos centros urbanos e industriais além de desenvolver mecanismos de gestão ambiental visando a sua recuperação (IFF, 2015, p.19).

Segundo os objetivos gerais do curso, citados acima, uma das funções do técnico em Meio ambiente é ajudar as empresas a se adequarem às obrigações legais e princípios do Desenvolvimento Sustentável. Esse objetivo pode ser encarado tanto como uma possibilidade de inserir o jovem no mercado de trabalho, quanto como um tipo de utilitarismo empresarial, que torna o jovem um instrumento para as empresas que querem liderar o mercado verde.

A possibilidade de tomar a dianteira no mercado verde favorece as empresas que iniciarem o processo de adequação à nova demanda ética presente no Desenvolvimento Sustentável. Com isso, o curso em questão se torna estratégico em nível microeconômico e promissor no nível macroeconômico, pois, como vimos 
anteriormente, o viés ambiental do neodesenvolvimentismo se dá justamente na busca de tomar a dianteira no processo de adequação à economia verde.

Por conta desse utilitarismo, a formação oferecida pelo Curso Técnico em Meio Ambiente reverbera os pressupostos neodesenvolvimentistas, logo, essa educação ambiental responde de forma emblemática mais aos anseios econômicos do que à expectativa dos técnicos formados.

\section{Considerações finais}

Esse trabalho buscou compreender a conexão entre o neodesenvolvimentismo vivido recentemente pela sociedade brasileira e seu interesse na educação ambiental. Diante disso, o primeiro ponto que buscamos compreender foi a perspectiva de meio ambiente pautada por esse projeto, ou seja, a noção de meio ambiente para o neodesenvolvimentismo. Constatamos uma defesa economicista do Desenvolvimento Sustentável, através do qual se defende a inserção do país numa "economia verde" capaz de superar a situação de subdesenvolvimento econômico e concomitante a isso proteger o meio ambiente.

O Programa Nacional de Acesso ao Ensino Técnico e Emprego (Pronatec) faz parte de uma estratégia de desenvolvimento econômico que inclui a educação como o baluarte para resolver o problema da baixa do crescimento. Esse ponto de vista declara a visão mercadológica do programa e a visão empresarial incutida nele.

Em relação às propostas do Pronatec voltadas para o meio ambiente, utilizamos a parceria entre o MEC e o MMA para entender o que se espera do Pronatec Ambiental. A análise da concepção de Desenvolvimento Sustentável para Ministério do Meio Ambiente segue a linha do neodesenvolvimentismo, isto é, considera o interesse econômico como orientador da pauta ambiental, sendo o meio ambiente importante no limite das possibilidades do desenvolvimento econômico. A vertente ambiental do Programa Nacional de Acesso ao Ensino Técnico e Emprego (Pronatec), portanto, oferece uma formação aos trabalhadores guiada pelo ponto de vista empresarial com uma pedagogia adaptativa aos novos processos demandados pela reestruturação produtiva do capital.

No Curso Técnico em Meio Ambiente, encontramos evidências dessa educação ambiental mais preocupada com o viés econômico do que com a sustentabilidade em si. Essa aproximação entre o desenvolvimento econômico e a sustentabilidade limita 
a capacidade transformadora da educação ambiental, sendo considerada apenas as possibilidades que permitam novos negócios.

Portanto, o curso responde a uma demanda específica do mercado brasileiro e obedece a um projeto estatal de estímulo ao desenvolvimento nacional. O interesse do curso, de modo geral é subsidiar as empresas da área ambiental, pois garante aos egressos uma visão ampla das vantagens e desvantagens de um investimento e ainda inclui em suas características a necessidade do trabalhador em se adaptar à reestruturação nas relações de produção do sistema capitalista. Transparece uma concepção utilitarista que legitima a degradação ambiental quando justificada pelo desenvolvimento econômico, seja pela extração de minérios, por fontes de energia ou pela produção agrícola.

Podemos concluir, no final, que a busca neodesenvolvimentista pelo concílio entre o desenvolvimento econômico e a sustentabilidade não faz mais do que legitimar o crescimento do país e relegar o meio ambiente à imposição de gerar lucro em suas propostas. Além disso, cogita-se a possibilidade de garantir o crescimento da economia través da geração de tecnologias verde, assim se propõe retirar a contradição entre os interesses ambientais e as necessidades do sistema do capital. Essa premissa foi identificada nos documentos e na prática da educação ambiental aqui examinada.

Para a Educação Ambiental Crítica (onde nos filiamos) não se pode ignorar os antagonismos de classes, deve-se entender que uma das principais características de uma sociedade desigual é o conflito de interesses e constatar a inevitabilidade do confronto político. Logo, a conciliação proposta pelo neodesenvolvimentismo é problemática para a transformação da realidade socioambiental, sobretudo, por limitar as ações ambientais à esfera dos interesses econômicos.

Embora nossas análises tenham sido restritas ao período inicial do século $X X I$ (onde o governo tinha uma base popular), percebemos nos tempos que se seguiram um recrudescimento da perspectiva mercadológica na área educacional e ambiental. Se antes havia uma tentativa de conciliação dos interesses, atualmente há uma desmoralização da pauta ambiental, apenas a vantagem econômica é considerada ao se propor políticas públicas. O que localizamos neste trabalho como um problema se aprofundou ainda mais, muito mais após o período dos governos petistas. 


\section{Referências}

BOFF, L. Sustentabilidade: o que é - o que não é. 1. Ed. Petrópolis, RJ: Vozes, 2012.

BOMFIM, A. M. O (Sub) Desenvolvimento (In)Sustentável: A Questão Ambiental nos países periféricos latino-americanos. Trabalho Necessário. Rio de Janeiro, ano.8, n. 10. Rio de Janeiro, UFF, 2010.

. A Questão Ambiental Diante do Paradoxo de Lula; Ampliando a reflexão-ação do Educador ambiental. In: ROÇAS, Giselle; ANJOS, Maylta Brandão dos. Reflexões Sobre a Prática e a Teoria da Educação Ambiental. Editora Publit. Rio de Janeiro, RJ. 2014.

BRASIL. Lei $\mathrm{n}^{\circ}$ 12.513, de 26 de outubro de 2011. Institui o Programa Nacional de Acesso ao Ensino Técnico e Emprego (Pronatec). Diário Oficial da União, 27 out. 2011 (a). Disponível em: <http://www.planalto.gov.br/ccivil_03/_Ato20112014/2011/Lei/L12513.htm>. 2011. Acesso em: 02 jan. 2019.

Grupo de Trabalho Interministerial Juventude e Meio Ambiente. Programa Nacional de Juventude e Meio Ambiente PNJMA - Brasília. 2013. Disponível em:<http://www.mma.gov.br/images/arquivos/responsabilidade_socioambiental/juven tude/Relatorio_GTI\%20JUVMA-FINAL.pdf>

. Ministério do Meio Ambiente. Plano Nacional de Juventude e Meio Ambiente

PNJMA $\quad-\quad$ Brasília. $2015 . \quad$ Disponível em: $<$ http://www.mma.gov.br/images/arquivos/responsabilidade_socioambiental/juventud e/publicacao_versao3.pdf>

BRESSER-PEREIRA, L. C. Empresários, O Governo do PT e o Desenvolvimentismo. Revista de Sociologia e Política, v. 21, n. 47, P. 21-29, 2013.

CASTIONI, R. Planos, projetos e programas de educação profissional: agora é a vez do PRONATEC. Ciências Sociais e Humanas, Santa Maria, v. 26, n 1, 2013, p. 25-42.

CHESNAIS, F.; SERFATI, C. "Ecologia" e condições físicas de reprodução social: alguns fios condutores marxistas. Crítica Marxista. $n^{\circ}$ 16. São Paulo: Editora Boitempo, 2003.

DELUIZ, N.; NOVICKI, V. Trabalho, Meio Ambiente E Desenvolvimento Sustentável: Implicações Para Uma Proposta De Formação Crítica. Boletim Técnico Senac, 2004.

DUARTE, N. Vigotsky e o aprender a aprender: crítica às apropriações neoliberais e pós-modernas da teoria Vigotskyana. 2.ed. Editora Autores Associados, 2001.

FRIGOTTO, G. A Produtividade da Escola Improdutiva: um (re)exame das relações entre educação e estrutura econômico-social capitalista. 9.ed. São Paulo: Cortez, 2010. ISBN 978-85-249-1640-3

GUIMARÃES, M. A formação de Educadores Ambientais. 8. Ed. Campinas, SP: Papirus, 2012. 
IFF - Instituto Federal Fluminense. Projeto Pedagógico do Curso Técnico em Meio Ambiente. Campos dos Goytacazes (RJ), 2015.

KUENZER, A. Exclusão includente e inclusão excludente: a nova forma de dualidade estrutural que objetiva as novas relações entre educação e trabalho. In: Lombardi, J.; Saviani, D.; Sanfelice, J. (Org.). Capitalismo, trabalho e educação. 3.ed. São Paulo: Autores Associados; histedbr, 2005. p. 77-96.

LAYRARGUES, P. P. Do ecodesenvolvimento ao desenvolvimento sustentável: evolução de um conceito? Revista Proposta, Rio de Janeiro, v. 24, n. 71, p. 1-5, 1997.

LIMA, G. F. C.; LAYRARGUES, P. P. Mapeando as macro-tendências políticopedagógicas da educação ambiental contemporânea no Brasil. VI Encontro Pesquisa em Educação Ambiental. Ribeirão Preto, set. 2011.

LOWY, M. Crise ecológica, crise capitalista, crise de civilização: A alternativa ecossocialista. Caderno CRH, v. 26, n. 67, p. 79-86, 2008.

MANACORDA, M. A. Marx e a pedagogia moderna. Campinas: Editora Alínea, 2007.

MERCADANTE, A. As Bases do Novo Desenvolvimentismo no Brasil: análise do Governo Lula (2003-2010). Tese de Doutorado apresentada ao Instituto de Economia da Universidade Estadual de Campinas UNICAMP, p. 356, 2010.

POCHMANN, M. Desafios do desenvolvimento brasileiro. Educação \& Sociedade, v. 34, n. 124, p. 705-722, 2013.

VENTURA, J. P.; LESSA, L. L.; SOUZA, S. C. V. Pronatec: ampliação das ações fragmentárias e intensificação da privatização da formação do trabalhador. Revista Trabalho Necessário, ano 16, n. 30, 2018. 